\title{
El Patronato «Juan de la Cierva» (1939-1960). III Parte: La investigación Científica y Tecnológica
}

\section{Santiago López García}

Arbor CLXII, 637 (Enero 1999), 1-32 pp.

El presente artículo es el último de una trilogía cuyas partes precedentes han sido publicadas en los números anteriores de Arbor. Ya hemos tratado los orígenes, la organización y la financiación del Patronato. Ahora, nos fijaremos en la investigación científica y tecnológica que se llevó a cabo en el periodo de la "autarquía económica" (epigrafe 5). Al final, exponemos las conclusiones y los apéndices y bibliografía comunes a los tres escritos.

\section{La investigación en el Patronato "Juan de la Cierva" entre 1946 y 1953.}

El valor tecnológico de lo que se investigó en el PJC no se puede saber por la repercusión industrial de cada investigación en los productos vendidos por las empresas. Aunque en el PJC estaba perfectamente establecido el canon que debía pagar cualquier firma que fabricara algún producto aprovechando una patente del PJC, lo cierto es que esto sólo funcionaba cuando se trataba de empresas completamente ajenas al INI. Esta situación sólo ocurrió una vez, así que el resto de transferencias de tecnología no las podemos contabilizar económicamente ${ }^{1}$. El problema es que las transferencias iban al INI sin coste alguno. Estimar el valor de la tecnología transferida podría llevarnos 
a compararla con el valor de los préstamos otorgados por el INI en favor del PJC, más todas las sumas de dinero llegadas al PJC gracias a la labor de captación del INI, lo cual incluiría buena parte de la exacciones. Siguiendo esta línea de análisis volveríamos a repetir lo expuesto en el capítulo anterior, de manera que debemos plantear el problema desde otra perspectiva menos economicista, y pasar a una más tecnológica, que nos permita averiguar si cualitativamente merecía la pena la investigación. Es decir, si la calidad de la investigación era aceptable o no. Lo revelador de este planteamiento es que nos indica si la tendencia, en cuanto a la calidad de la investigación realizada se refiere, era creciente o no, y a partir de aquí podemos juzgar, que si la tendencia era de un signo u otro entonces la inversión tenía más o menos sentido en cuanto a la producción de tecnología.

Este análisis sólo se debe hacer cuando la inversión es creciente, porque si no es fácil deducir que la falta de fondos incide negativamente en la calidad de la investigación. Es por ello que nuestro período de análisis abarca de 1946 a 1953, años durante los cuales la situación económica del Patronato era buena.

Veamos primero el método que hemos seguido para clasificar la investigación realizada por el PJC y, segundo, los resultados de aplicar el método.

En 1931 W. G. Hoffmann estableció la más antigua tipología de la industrialización. El método utilizado era muy sencillo: el cociente del valor añadido bruto en las industrias de bienes de consumo por el de las industrias de bienes de inversión ${ }^{2}$. Este cociente nos parece lógico como indicador del grado de industrialización, porque producir bienes de inversión tiene un grado de complejidad, debido a la tecnología de la que dependen, mayor que fabricar bienes de consumo. Además, los bienes de inversión permiten crear nuevas industrias, mientras que los bienes de consumo son bienes finales.

En el mundo de la tecnología el grado de complejidad de las actividades también existe. Las invenciones, prototipos e innovaciones son los «bienes" más complejos y que dan la pauta para realizar otros mejores. Por contra, los análisis rutinarios, los sondeos, las descripciones, las reproducciones, los controles de calidad, las acomodaciones a normativas y las mejoras de productos y servicios realizadas con técnicas pretéritas son "bienes" menos complejos, que operan como tareas rutinarias en un proceso de investigación, y que por mucho que se mejoren y se repitan no darán invenciones ni innovaciones. Llegados a este punto podemos establecer un cociente entre las actividades de alta complejidad y las de baja complejidad cuya tendencia 
a lo largo de un período nos indicará si una economía, empresa o institución está o no siguiendo un proceso de incremento de la complejidad tecnológica, no sólo en función del monto creciente o decreciente de su inversión en $\mathrm{I}+\mathrm{D}$, sino en relación a cómo lo invierte. $\mathrm{Si}$ la tendencia no es progresiva estaremos frente a un fenómeno de fracaso en el proceso de modernización tecnológica.

Es esta tendencia la que buscaremos para confirmar la creciente o decreciente complejidad de la actividad tecnológica realizada por el PJC, pero antes queda un escollo. Al establecer una analogía entre el cociente de Hoffmann y el de complejidad tecnológica se plantean dos problemas en uno: ¿qué es un producto tecnológico y cuál su valor añadido?

$\mathrm{La}$ actividad industrial produce bienes en los que podemos contabilizar el valor añadido, pero en la actividad tecnológica se produce información que puede ser o no publicada, patentada, transmitida o simplemente acumulada en forma de conocimientos en la mente de un tecnólogo. Si sólo medimos la actividad tecnológica por los artículos y las patentes dejamos parte de la actividad y sus frutos sin contabilizar. Entonces, ¿cuál es la unidad de la actividad tecnológica? Evidentemente tiene que ser una unidad de información cuya agregación nos de toda la actividad tecnológica realizada.

Tanto en la industria como en las instituciones de investigación se asignan presupuestos por objetivos y éstos se enmarcan en proyectos de investigación. Es precisamente el proyecto de investigación por objetivos la unidad de información que nos interesa utilizar. La información que en ellos se produce puede, desde quedar acumulada en los conocimientos del equipo de tecnólogos, hasta negociarse con ella en forma de una patente. Posteriormente la información que contiene la patente o el prototipo se vende como un derecho porcentual en cada unidad del producto fabricado industrialmente. Esta segunda parte ya es actividad industrial, por ello la actividad tecnológica que está tras cada proyecto finaliza antes de la comercialización estandarizada. Sin embargo, un producto industrial que se vende en el mercado puede sufrir mejoras ulteriores - de acuerdo con la teoría del ciclo de vida del producto- generando a veces nuevos proyectos de investigación.

Una vez establecido que el proyecto de investigación es la unidad de la actividad tecnológica, ¿que cabe entender por complejidad tecnológica? Cuanto mayor es la complejidad de un proyecto de investigación mayor es el componente de valor añadido. En una invención, innovación o prototipo el valor añadido está dado por el trabajo de tecnólogos y técnicos, más el servicio del instrumental y de las instalaciones -especialmente de las que representan acumulación de co- 
nocimientos, como bibliotecas, centros de documentación y bases de datos-, menos la tecnología intermedia (patentes compradas y asistencia técnica pagada) y los productos intermedios utilizados para crear los prototipos y realizar las analíticas - partidas que serán mínimas en comparación con los costes en horas de científicos y el valor del instrumental utilizado en ocasiones para un sólo proyecto-. Por contra, en los proyectos de baja complejidad el valor añadido desciende al mínimo, ya que el coste de las partidas en tecnología intermedia y bienes intermedios es máxima. Puede darse el caso de que un análisis rutinario tenga un alto valor añadido si se hace con instrumentos complejos y en instalaciones caras, pero esto no es usual, ya que los análisis se vuelven rutinarios cuando el método y el instrumental están estandarizados. Así llegamos a la clave de la relación complejidad con valor añadido. Un proyecto es complejo primero en función del objetivo, que va desde la innovación hasta las tomas de datos para un análisis descriptivo de un fenómeno, y segundo, en función de la mayor o menor estandarización de las técnicas empleadas en el proyecto. Los proyectos de investigación son complejos, es decir tienen un alto valor añadido, cuando sus objetivos son obtener invenciones, innovaciones, prototipos, experiencias piloto y nuevos métodos de fabricación, más todas las mejoras en los procesos de fabricación, en los productos, en el diseño, en el aprovechamiento de residuos y en la comercialización que se intenten utilizando técnicas recientes aún no estandarizadas. En sentido inverso, juzgamos que los proyectos de investigación son de baja complejidad tecnológica, es decir, tienden a tener un bajo valor añadido, cuando sus objetivos son nformes documentales, bibliografías, análisis rutinarios, sondeos, encuestas, descripciones, análisis de prospectiva, utillaje y reproducciones, reparaciones y mantenimiento, confección de manuales e instrucciones, acomodación a normativas, control de calidad, estudios de seguridad y organización del trabajo y todas la mejoras de procesos y productos realizadas con técnicas estandarizadas, o basándose en la compra de patentes y en la formalización de contratos de transferencia de tecnología ${ }^{3}$.

Por último, el análisis de Hoffmann es macroeconómico ya que decimos que una economía está más industrializada cuanto mayor es el valor añadido producido por los bienes de inversión, pero no podemos decir lo mismo microeconómicamente, pues nadie diría que una empresa que produce bienes de consumo está menos industrializada que una que produce bienes de equipo. Sin embargo, sí podemos decir que una institución científica está avanzando tecnológicamente si sus proyectos de investigación terminan siendo innovaciones, prototipos o invenciones. 
Una vez superados los escollos volvemos al punto de partida, que es conocer la tendencia del cociente entre proyectos de alta y baja complejidad tecnológica en el PJC, como indicador del éxito o fracaso de la institución.

Lo primero que se impone a la hora de analizar los proyectos de investigación es conocer su evolución numérica a lo largo del período estudiado. El cuadro 5.1. muestra que los proyectos fueron aumentando en número hasta 1951, fecha a partir de la cual empezó una caída seguida de una estabilización. En función de las tasas de crecimiento el esfuerzo más intenso se dio de 1949 a 1951 . Destaca en este cuadro la elevación general en el número de proyectos entre 1950 y 1951 debida, en buena medida, al núcleo de institutos ligados a la iniciativa en política industrial de Suanzes, como el IN Combustible, el IN Electrónica, el IH Acero, el I Soldadura, el INR Trabajo y el D Óptica - sus medias anuales son las más altas tal como muestra el cuadro en su última columna, y su participación con respecto al total de proyectos era de un $33,3 \%$ en 1950 y de un 38,7 en 1951-.

CuAdRo 5.1. Proyectos de investigación del Patronato "Juan de la Cierva" (1946-1953). División por institutos

\begin{tabular}{|l|r|r|r|r|r|r|r|r|r|r|}
\hline INSTITUTOS & 1946 & 1947 & 1948 & 1949 & 1950 & 1951 & 1952 & 1953 & Totales & Media anual \\
\hline ILT Quevedo & & & 4 & 1 & 3 & 20 & 15 & 32 & 75 & 12,50 \\
IIT Barcelona & 6 & 9 & 8 & 18 & 12 & 13 & 14 & 11 & 91 & 11,38 \\
IN Electrónica & & & 2 & 6 & 8 & 19 & 36 & 26 & 97 & 16,17 \\
Laffón-Selgás & 5 & 2 & 3 & 3 & 4 & 6 & 2 & 3 & 28 & 3,50 \\
D Optica & & & & & 5 & 15 & 18 & 14 & 52 & 13,00 \\
D Silicatos & & & & & 4 & 4 & 5 & 12 & 25 & 6,25 \\
I Forestal & & & 8 & 5 & 19 & 24 & 13 & 2 & 71 & 11,83 \\
II Pesqueras & & & & 4 & 12 & 13 & 12 & 17 & 58 & 11,60 \\
DQ Vegetal & & & & & 5 & 20 & 5 & 14 & 44 & 11,00 \\
IE Grasa & & 8 & 4 & 5 & 11 & 10 & 11 & 12 & 61 & 8,71 \\
S Fermentaciones & & 5 & 7 & 6 & 4 & 11 & 9 & 7 & 49 & 7,00 \\
D Plásticos & & 2 & 3 & 3 & 5 & 4 & 5 & 4 & 26 & 3,71 \\
IN Combustibles & 12 & 8 & 13 & 18 & 17 & 39 & 29 & 15 & 151 & 18,88 \\
IH Acero & & 29 & 6 & 5 & 10 & 8 & 13 & 10 & 81 & 11,57 \\
I Soldadura & & & 1 & 2 & 3 & 8 & 11 & 3 & 28 & 4,67 \\
ITC Edificación & 5 & 1 & 12 & 8 & 18 & 13 & 5 & 23 & 85 & 10,63 \\
INR Trabajo & & & & 6 & 10 & 9 & & & 25 & 5,00 \\
T Subvenciones & & 2 & 9 & 9 & 9 & 16 & 12 & 15 & 72 & 10,29 \\
Otros & 5 & 1 & & & & 1 & 12 & 9 & 28 & 3,50 \\
TOTALES & 33 & 67 & 80 & 99 & 159 & 253 & 227 & 229 & 1.147 & \\
Total de & & & & & & & & & \\
crecimiento & & 103,03 & 19,40 & 23,75 & 60,61 & 59,12 & $-10,28$ & 0,88 & & \\
\hline
\end{tabular}

Fuente: Base de datos 1147 -PJC.DBF - Lopez García (1994a). 


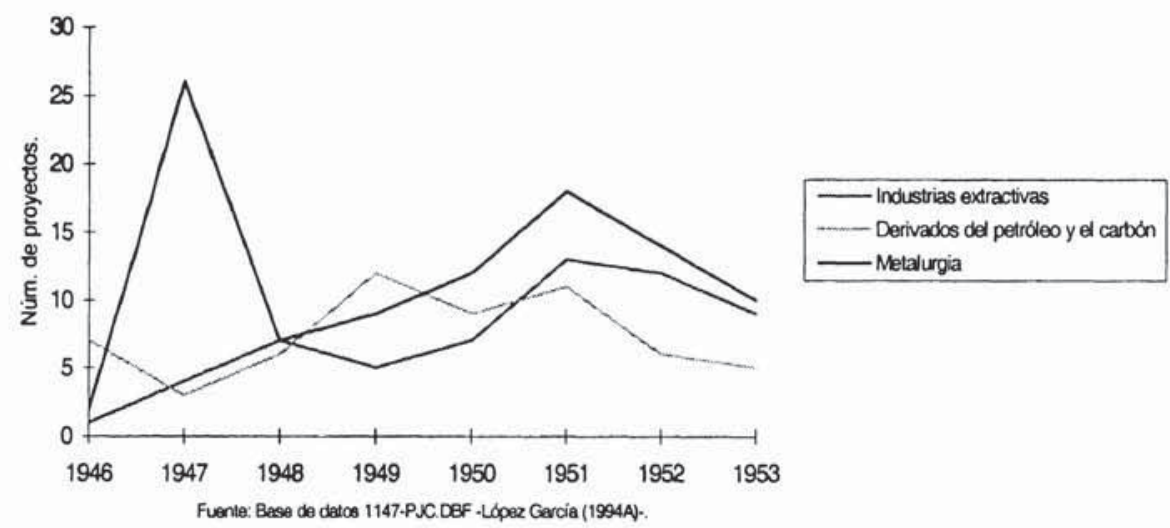

La importancia de la química fue predominante en el PJC, tanto desde el punto de vista de los proyectos ligados al INI, a través del IN Combustible, como en lo referente a las investigaciones unidas a la química de los productos del campo -DQ Vegetal, IE Grasa y S Fermentaciones - dependientes en última instancia de Lora Tamayo. Sin embargo, como muestra el gráfico 5.1, ninguna de las iniciativas de los institutos más ligados al INI consiguió atenuar la fuerza del descenso en el número de proyectos a partir de 1951. Además, se destaca el revés que se produjo en la evolución del número de los proyectos referidos a los productos derivados del petróleo y del carbón, es decir, los proyectos del IN Combustible, que ya en 1949 empezaron a disminuir, culminando esta tendencia en 1952 cuando el CI ENCASO abandonó el PJC.

El cambio de 1951 en la trayectoria de los proyectos también fue el fruto de la propia evolución de la actividad del Patronato. Después de cinco años de estudios e informes para que se iniciasen diferentes líneas de investigación, era lógico que este tipo de trabajos descendieran, a la vez que fueran tomando mayor importancia los proyectos que estaban ligados directamente a las actividades previas a la fabricación - control de calidad, acomodación a normativas, manuales, utillaje y reproducciones, métodos de fabricación e $\mathrm{I}+\mathrm{D}$ específica del inicio de la fabricación-. Este proceso se puede reconocer en el gráfico 5.2. Pero la transformación interna del PJC fue más rica que esta apre- 


\section{El Patronato «Juan de la Cierva» (1939-160)}

ciación. Tras los estudios, informes y análisis rutinarios el segundo tipo de proyectos eran los que conseguían mejoras con las técnicas conocidas del momento - véase la curva de Mejoras con técnicas modernas del gráfico 5.2.- Es decir, el PJC asentaba gran parte de su labor en la asimilación de técnicas que estaban de acuerdo con los estándares internacionales, lo cual acreditaba al Patronato como una institución "al día" y dotada del material adecuado para realizar las investigaciones. Sin embargo, desde 1950 esta situación varió. El cambio fundamental en la evolución de los proyectos vino dado porque ahora eran aún más numerosos los proyectos que implicaban mejoras, pero el incremento no se basaba en técnicas novedosas, sino que se apoyaba en técnicas ya caducas o muy tradicionales. El problema tenía dos aspectos. Por un lado, estaban los nuevos institutos de química que se habían incorporado al PJC, como el DQ Vegetales. Este instituto estaba formalizando sus primeros trabajos y, lógicamente, no tenía la riqueza de medios suficientes para llevar a cabo mejoras con un alto valor añadido científico proveniente de la utilización de métodos avanzados de investigación y, sin embargo, había iniciado numerosos proyectos ${ }^{4}$. Por otra parte, estaba el problema del ILT Quevedo, cada vez más impelido a tener que desarrollar sus prototipos con técnicas más artesanales que industriales. Esta situación fue insostenible para el Instituto a mediados de los años cincuenta, y terminó resolviéndose en 1957 cuando su sección de talleres fue traspasada a ENOSA.

GrÁFICO 5.2. Proyectos de investigación del Patronato "Juan de la Cierva"

(1946-1953). División atendiendo a la complejidad del trabajo de investigación

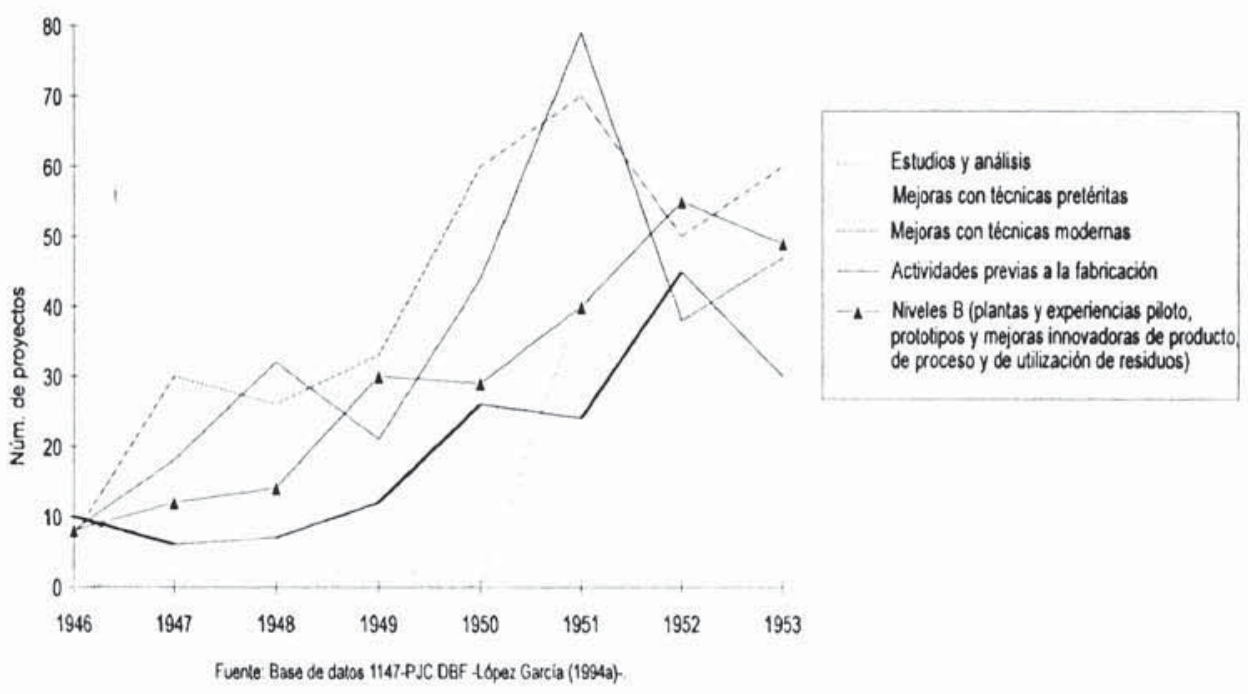


El gráfico 5.2. también ofrece una información que pone de manifiesto la intensidad del esfuerzo del PJC por conseguir el acercamiento tecnológico. Bajo el epígrafe de Niveles B se encuentran todos aquellos productos científicos y tecnológicos, que implican innovaciones, invenciones y mejoras dentro del "estado del arte" de cada área científica o tecnológica, es decir, los proyectos de alta complejidad tecnológica. La curva del gráfico indica que el empeño en este tipo de proyectos fue el más constante. Carece de las pronunciadas variaciones de los otros niveles de complejidad en su tendencia general -véase también la tasa de crecimiento anual del cuadro 5.2 columna sexta-. Ahora bien, si se unen todas las demás categorías de proyectos bajo un epígrafe - niveles de tipo A de baja complejidad tecnológica- se obtiene una curva cuya tendencia es similar a la de los niveles B. De hecho, a lo largo del período las tasas de crecimiento anual media son semejantes: 35,34 y 30,27 respectivamente - véase el cuadro 5.2 .- , pero es precisamente esta diferencia de 5,07 puntos la que indica hasta qué grado el intento de acercamiento tecnológico se consiguió o no.

CUADRo 5.2. Proyectos de investigación del Patronato "Juan de la Cierva" según niveles de complejidad tecnológica

\begin{tabular}{|c|c|c|c|c|c|}
\hline Años & $\begin{array}{c}\text { Proyectos de } \\
\text { niveles A }\end{array}$ & $\begin{array}{c}\text { Proyectos de } \\
\text { niveles B }\end{array}$ & Totales & $\begin{array}{c}\text { TCA de los } \\
\text { niveles A }\end{array}$ & $\begin{array}{c}\text { TCA de los } \\
\text { niveles B }\end{array}$ \\
\hline 1946 & 25 & 8 & 33 & & \\
1947 & 55 & 12 & 67 & 120,00 & 50,00 \\
1948 & 66 & 14 & 80 & 20,00 & 16,67 \\
1949 & 69 & 30 & 99 & 4,55 & 114,29 \\
1950 & 130 & 29 & 159 & 88,41 & $-3,33$ \\
1951 & 214 & 40 & 254 & 64,62 & 37,93 \\
1952 & 171 & 55 & 226 & $-20,09$ & 37,50 \\
1953 & 180 & 49 & 229 & 5,26 & $-10,91$ \\
Totales & 910 & 237 & 1.147 & & \\
TCA media & & & & & 35,34 \\
(1946-1953) & & & & & 30,27 \\
\hline
\end{tabular}

Fuente: Base de datos 1147 -PJC.DBF - Lopez García (1994a).

$\mathrm{TCA}=$ Tasa de crecimiento anual.

Niveles A (estudios, análisis, actividades previas a la fabricación y mejoras con técnicas usuales)

Niveles B (plantas y experiencias piloto, prototipos y mejoras innovadoras)

La tendencia de la curva de los proyectos del nivel B en el gráfico 5.2 indica que existió un intento de acercamiento tecnológico, y que fue de una intensidad notable, puesto que la tasa de crecimiento anual 
se situó en el 30,27, pero la cuestión es saber si el esfuerzo fue el adecuado para el conjunto del PJC.

Para responder a esta cuestión lo primero que se debe hacer es plantear, qué es en síntesis un proceso de acercamiento. Es preciso relacionar la teoría con el análisis empírico del PJC, por ello se ha de dar una definición que sea útil en referencia a ese análisis.

El fenómeno de acercamiento tecnológico ocurrido en una institución es el éxito a la hora de mantener una actividad científica y tecnológica que permita tener cada vez una mayor productividad en los niveles de complejidad altos - del tipo B-, en relación al conjunto de la actividad tecnológica que se desarrolla en dicha institución. Por tanto, el acercamiento tecnológico es un hecho que depende de los vínculos que se establezcan entre los niveles A y B de complejidad tecnológica. Cuando la tasa de crecimiento del nivel B supera, aunque sea mínimamente, a la del nivel $\mathrm{A}$, entonces se puede suponer que se está frente a una institución o empresa que logra un acercamiento tecnológico. La manera más sencilla de expresar matemáticamente esta noción es plantear una relación porcentual entre los proyectos de nivel A y el total de proyectos. Lo que se obtiene es una curva que indica el equilibrio entre proyectos de tipo A y B por medio del tanto por ciento que representan los proyectos de nivel tipo $\mathrm{B}$ con respecto al total. Si la tendencia de la curva es estable o decreciente el fenómeno de acercamiento no se produce. Esta incapacidad estará determinada por dos variables: la falta de capital humano y la falta de instalaciones y material de investigación. Cuando la incapacidad se debe al primer problema no cabe más medida que la formación previa de capital humano en instituciones dedicadas a tal cometido. Sin embargo, cuando el problema es debido a una falta de recursos hay dos opciones: un plan de ajuste de la institución hasta que la tendencia de los proyectos de tipo B sea creciente, o un incremento de los recursos con el mismo fin. Si se opta por una "estabilización" de la institución, adecuando el número de proyectos y su complejidad a los fondos existentes, hay que contar con el riesgo de aumentar la especialización en áreas científicas y tecnológicas maduras.

En el PJC la curva de equilibrio entre los niveles de tipo B y A tenía una tendencia ligeramente negativa, tal como muestra el gráfico 5.3. Ello indica que el acercamiento tecnológico no se consolidó en este período.

Dos fueron las razones de esta incapacidad para lograr el acercamiento tecnológico: primera, la falta de capital humano y, segunda, la carencia de recursos financieros destinados a la investigación, mas 
GRÁfICO 5.3. Equilibrio entre los proyectos de investigación de los niveles A y B de complejidad tecnológica en el Patronato "Juan de la Cierva" (1946-1953).

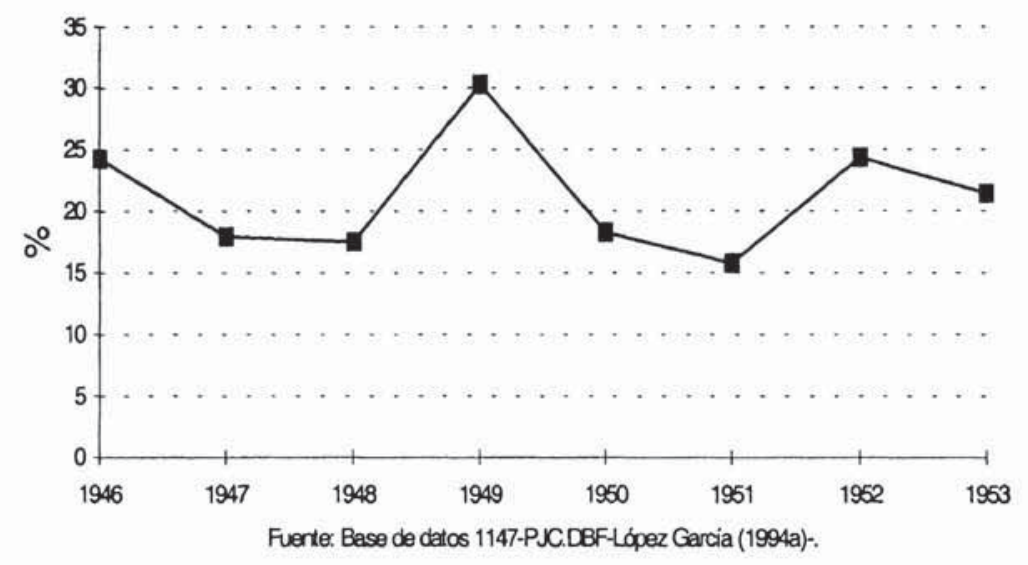

en este período los ingresos fueron crecientes. No obstante, una mirada atenta a las partidas del gasto indica dónde radicaba el segundo de los problemas. El esfuerzo dedicado a la construcción de edificios detrajo fondos, que de haberse destinado a instrumentos y personal hubieran revertido en un mayor número de proyectos de investigación de nivel $\mathrm{B}$.

Después de 1954, una vez finalizadas las primeras inversiones en edificios, el PJC estuvo en condiciones de potenciar sus investigaciones de nivel B, sin embargo, se encontró con que sus ingresos fundamentales (subvenciones estatales y exacciones a la industria) se habían estabilizado. La crisis de la institución empezó en este momento, aunque también fue la consolidación de una fase en el que varios proyectos e innovaciones, que respondían a las directrices de política tecnológica marcadas desde mediados de los años cuarenta, estaban consiguiendo sus primeros logros. Sin embargo, era un mal momento para aquel tipo de proyectos de corte autárquico. La posibilidad de contar con mayores aportes de tecnología extranjera, en especial estadounidense desde 1953, debilitaron cualquier opción nacionalista. Esta situación quedó de manifiesto en los objetivos socioeconómicos implícitos en los proyectos. El caso más evidente donde se fracasó en el acercamiento tecnológico fue en el aprovechamiento industrial de residuos, un campo típico del espíritu autárquico.

En el lado opuesto a lo que sucedía con los residuos estaba el excelente comportamiento de las telecomunicaciones, debido en su mayor 
parte a los prototipos diseñados por los científicos alemanes del IN Electrónica. El equilibrio entre los niveles A y B queda volcado a favor de los niveles $\mathrm{B}$, que nunca bajan de $68 \%$ con respecto al conjunto de los proyectos. Evidentemente la actividad investigadora realizada en el IN Electrónica era competitiva con la de otros centros extranjeros.

En 1953 el IN Electrónica llegó a uno de sus mejores momentos desde el punto de vista tecnológico. Los diseños de los radares RXN, empezados a mediados de 1951, habían concluido con la construcción de varios prototipos. Los propios científicos catalogaban algunos de sus diseños como de segunda línea internacional, como el RXN-1, que estaba indicado para el seguimiento de vuelos de aviones y el movimiento de borrascas hasta $80 \mathrm{Km}$. Pero, otros radares como el RXN-2, adecuado para la artillería, o el GCA , indicado para el aterrizaje de aviones en situación de escasa visibilidad, incorporaban innovaciones en su manejo y prestaciones ${ }^{5}$. Prueba de ello es que la empresa alemana Einsenwerke Kaiserslautern se decidió a fabricarlos, pero el proyecto fue abandonado porque, en 1955, justo cuando se iba a empezar la producción en serie, EE.UU. apoyó con su armamento la defensa de Alemania, lo que saturó rápidamente el mercado germano ${ }^{6}$.

Otro éxito relativo de acercamiento tecnológico se consiguió en los proyectos relacionados con los minerales no metálicos. Aunque el número de proyectos no fue muy elevado la tendencia en el equilibrio entre niveles fue positiva. Entre las líneas de investigación destacables se encuentra la de las aplicaciones industriales de las bentonitas españolas para la obtención de jabones, que dependía del D Silicatos. Pero fue el ITC Edificación, el que a través de sus trabajos sobre materiales de construcción, encabezaría las investigaciones de minerales no-metálicos ${ }^{8}$.

La misión del ITC Edificación fue el diseño de los elementos a construir (características mecánicas, condiciones de fabricación, materiales, diseño del utillaje para montaje y estudio de tiempos de operación). Cada proyecto de este tipo superaba el plazo del año y suponía el esfuerzo de varios especialistas. El trabajo de ensayo dio lugar al estudio de resistencia e impermeabilidad de ladrillos, fortaleza de piezas de hormigón y calidades de yesos. Estos estudios marcaron la pauta por la que debían regirse los productores de los materiales a utilizar. Entre los objetivos se encontraban: la obtención de un hormigón pretensado de poco peso pero resistente para aumentar las economías de transporte, la sustitución de la madera exterior (dinteles) por hormigón para ahorrar madera escasa, la impermeabilidad del yeso y nuevos sistemas de obra de ladrillo. Con todo ello se estimó que se 
conseguía una reducción en los costes del $30 \%$ con respecto a los métodos tradicionales ${ }^{9}$.

La trascendencia de las actividades económicas relacionadas con los proyectos de investigación presentados hasta aquí en este apartado, no es tan importante como lo que sucedía con los proyectos relacionados con la química, al menos a partir de 1950. El equilibrio entre los proyectos de los niveles A y B en la química sufrió un fuerte descenso entre 1949 y 1950, para después recuperarse desde 1951. En buena parte esta tendencia siguió los avatares del IN Combustible, que era el que llevaba a cabo un mayor número de proyectos.

Sin embargo, en la recuperación que se da desde 1951 influyen otros proyectos, ligados a Lora Tamayo, como los aductos de urea del IE Grasa. Al menos en 1952 estas investigaciones fueron calificadas de pioneras en el mundo ${ }^{10}$. Sin embargo, no fueron muchas las aplicaciones industriales que se consiguieron. En 1956 se iniciaron los estudios de formación de aductos con jabones en busca de mejores productos, pero no se alcanzó la fase industrial en ningún caso.

En resumen, el PJC tuvo que potenciar los niveles de tipo A para, sencillamente, mantener la capacidad de imitar. Hubo, por tanto, una incapacidad general de la institución para mantener el esfuerzo en los niveles de tipo B. El PJC, tras su intento de capitanear un proceso de acercamiento tecnológico, se vio forzado a conformarse con asegurar el conocimiento de la tecnología extranjera por medio de procesos de imitación basados en proyectos de nivel tipo $\mathrm{A}^{11}$. Este fracaso determinó la incapacidad del PJC para ser la institución directora de un proceso de acercamiento tecnológico, lo que condujo, desde mediados de los años cincuenta, a una situación de falta de objetivos en la política científica y tecnológica que duraría hasta finales del decenio.

\section{Conclusiones}

A principios del siglo XX los países más avanzados del mundo habían creado instituciones de investigación y desarrollo capaces de conectar el mundo de la investigación científica, propia de las universidades, con el del desarrollo industrial, característico de los laboratorios de las fábricas. En España no apareció una institución similar hasta 1931. En este año nació la FNICER, pero su vida fue efímera, ya que la guerra civil impidió su normal desarrollo.

Tras la contienda el nuevo Gobierno puso en pie el Patronato "Juan de la Cierva" del CSIC con el objetivo de implantar una institución 
de investigación y desarrollo. El Patronato fue en algunos aspectos el sucesor de la FNICER, puesto que heredó de ésta los bienes y buena parte de los objetivos. Sin embargo, los primeros cinco años estuvieron marcados por la falta de definición en el tipo de laboratorios y proyectos de investigación a desarrollar. De cualquier manera el espíritu de reforma de la FNICER fue sustituido por el de la autarquía, y las investigaciones pasaron a centrarse en los problemas económicos del momento: la reconstrucción de las infraestructuras y el asegurar a la industria los combustibles básicos (carbón y petróleo) a partir de materias primas nacionales.

A lo largo del primer lustro de los años cuarenta se fortaleció esta línea de actuación, mas el empuje definitivo llegó en 1946, año en el que el Presidente del INI, Suanzes, toma las riendas del Patronato, con el objetivo de pergeñar un centro de investigación a la medida de las necesidades del INI. Para conseguirlo se necesitaba un salto de escala. En 1946 el presupuesto del PJC creció hasta superar los 15 millones de pesetas -más o menos la misma cantidad que recibía el resto del CSIC- multiplicando así por siete su dotación económica. A partir de ese momento se abría un nuevo período marcado por unos objetivos muy definidos: aprovechamiento de todo tipo de residuos industriales, potenciación de combustibles nacionales, apoyo a las investigaciones sobre edificación y construcción y creación de centros especializados en las tecnologías avanzadas del momento (electrónica).

El Patronato se convirtió en una institución dotada económicamente por encima de la media de los centros científicos españoles, lo que provocó la petición de ayuda por parte de otros centros del CSIC y de las universidades dispuestos a trabajar en temas aplicados con tal de recibir parte del dinero. El PJC pasó así a decidir numerosas líneas de investigación, lo cual cambió totalmente sus posibilidades. Ya no sucedía como antes de 1945 cuando coexistían en el Patronato centros claramente de investigación técnica con otros de investigación aplicada pero de escaso contenido técnico. Ahora todos los institutos del PJC eran de investigación técnica, y si algún otro centro no perteneciente al Patronato quería ser subvencionado, debía realizar investigaciones dentro del marco de interés del PJC.

Una vez que el Patronato creció en el sentido señalado por Suanzes empezaron a reforzarse los lazos con el INI, pero las conexiones claras entre una y otra institución se desarrollaron muy lentamente, y en numerosos casos sin cumplir las expectativas iniciales.

Desde el principio la aventura del PJC estaba condenada al fracaso. En un país donde el mercado de tecnólogos era pequeño y había sido 
mermado por la guerra civil y sus consecuencias, el PJC era superfluo. La industria no podía demandar los servicios ni aprovecharse de los programas del PJC porque las empresas no tenían la posibilidad de contratar los tecnólogos suficientes como para embarcarse en actividades de investigación con el objetivo de innovar. Sin embargo, el PJC siguió adelante y pasó a ser una herramienta más en la política industrial protagonizada por el INI.

Siete institutos del PJC estuvieron bajo la dependencia directa del INI a la hora de decidir sus planes de investigación. Cuatro de ellos aparecían en los organigramas de una y otra institución (CI ENCASO, CE Eólica , CE Frío y DII Piritas), y en el caso de los otros tres (I Carbón, IH Acero y D Óptica), que pertenecían plenamente al PJC, sus objetivos eran marcados desde el INI. Aparte de las conexiones citadas el INI contactó permanentemente con el INR Trabajo, y de forma puntual con el II Pesqueras, el IIT Barcelona y el I Forestal. Estos vínculos más o menos institucionalizados entre ambos organismos fueron el fruto de las relaciones personales de un grupo de ingenieros militares encabezado por Suanzes y formado por J. Planell, A. Plana Sancho, O. Navascués, R. Beltrán y A. Fernández Ávila ${ }^{12}$.

J. Planell, la mano derecha de Suanzes desde los tiempos de las Comisiones de Movilización Industrial formadas a raíz de la I Guerra Mundial, fue a la vez presidente de ENCASO y del CI ENCASO, además participó en la remodelación del PJC a mediados de los años cuarenta ${ }^{13}$. A. Plana Sancho, un reputado comandante de artillería retirado que a lo largo de su vida había dirigido los laboratorios del ejército relacionados con la artillería -Laboratorio Metalúrgico Central de Artillería, Taller de Precisión y Laboratorio y Centro Electrotécnico de la Academia de Artillería- y trabajado en Altos Hornos de Vizcaya y en la Sociedad Anónima Echevarría como director técnico, asumió la dirección del IH Acero del PJC ${ }^{14}$. O. Navascués, que acaparó la investigación en la Armada, determinó buena parte de los planes del PJC, no sólo en el D Óptica, sino también en el IH Acero ${ }^{15}$. También fue el consejero delegado de ENOSA y uno de los protagonistas en el nacimiento de la JEN. R. Beltrán dirigió a la vez el Departamento de Alimentos del INI y el CE Frío del PJC ${ }^{16}$. Desde esta doble posición diseñó la Red del frío del INI. Mas entre todos ellos merece la pena destacar a Fernández Ávila. Entre sus ocupaciones tuvo las de vocal del Consejo Técnico de Marina Mercante del INI, miembro de la Comisión Permanente del PJC, director del INR Trabajo del PJC, director de Investigación Técnica del CSIC, presidente de la Dirección de Construcción e Industrias Navales del Ministerio de Marina, y terminó 
siendo presidente de la Empresa Nacional Siderúrgica SA (ENSIDESA). Suanzes desde 1942 se sirvió de él, como director de Investigación Técnica del CSIC, para acercar la política de investigación aplicada del CSIC a los principios de política industrial encarnados por el INI ${ }^{17}$.

Fernández Ávila siguió en el CSIC la estrategia de ganar autonomía para el PJC, para que una vez alcanzada Suanzes lo reorganizara. Suanzes se sirvió del Consejo Técnico Químico del INI para que éste estudiara el proceso de reorganización en función de sus planes como rector de la política industrial. Fernández Ávila y Gómez Aranda quedaron encargados de fraguar la reforma, extrayendo del CSIC los grupos de trabajo que interesaran y supeditando los centros de investigación aplicada existentes en el país a la dependencia económica y directiva del PJC ${ }^{18}$. La primera parte se consiguió en el mes de julio de 1945 , cuando Fernández Ávila se encontró con la capacidad suficiente para que sus funciones como director de Investigación Técnica del CSIC pasaran directamente a los órganos reglamentarios del PJC y desde allí se plantearan los contactos con el CSIC ${ }^{19}$. Desde aquel momento el PJC actuó como una institución acaparadora de la práctica totalidad de la investigación aplicada. Pero su fin no era el de dar al conjunto de la industria la tecnología para mejorar la producción española en términos generales, tal y como figuraba en su ideario.

Los intereses dominantes eran los del INI. Para este último organismo el PJC cumplía dos funciones: primera, informar sobre la posibilidad de "revalorizar» las materias primas y los residuos, lo cual condujo a la creación de empresas a raíz de las oportunidades tecnológicas detectadas con la "revalorización", y segunda, reconocer el "estado del arte" de las tecnologías en las que el INI quería iniciar actividades industriales, lo que implicaba utilizar la aparente cara científica del PJC para extraer información de las empresas privadas.

La obsesión por "revalorizar" se manifestó en los intentos de obtener coque basándose en carbones de ínfima calidad, sustitutos de la chatarra partiendo de minerales de hierro de baja ley, productos químicos procesando desperdicios agrícolas, lubricantes a partir de pizarras bituminosas y metales diversos utilizando piritas con escaso contenido en cobre. Sin duda fue la obstinación de producir coque con carbón de baja calidad la que ejemplifica mejor el objetivo de la "revalorización", que era intrínseco a la doctrina de la autarquía y la sustitución de importaciones.

Lo primero que hay que tener presente es que la "revalorización" del carbón se entendía como la consecuencia de aplicar una mejora técnica o agregar un conocimiento tecnológico a la obtención del coque, 
después de haberse logrado las mejoras devenidas de una explotación más eficaz o de un transporte más eficiente - estas mejoras de orden económico se daban por resueltas o fijas mientras no hubiese un proyecto para "revalorizar" el transporte o el trabajo-. El principio económico de la "revalorización" era el siguiente: la aplicación de tecnología y técnicas debía aumentar el valor de los bienes - especialmente de las materias primas - hasta que éste superara el que hubiera tenido en el mercado después de que se realizaran todas las mejoras posibles de eficiencia económica en la explotación y en el transporte -nótese que en el principio no se plantea que la "revalorización" deba ser abandonada si el coste del coque nacional es mayor que el del coque importado- Si los estudios e informes de tipo técnico concluían que, con la revalorización el nuevo valor del carbón de mala calidad iba a ser indiscutiblemente superior, porque se había transformado en coque, entonces la investigación proseguía y se pasaba a la fase de investigación semiindustrial.

Hasta ese punto el PJC era el encargado de marcar la pauta. Si sus análisis en el laboratorio conseguían la "revalorización" entonces era misión del INI la industrialización, es decir, el cambio de escala en la obtención de la "revalorización". Éste era el momento crítico, debido a que se necesitaban conocimientos tecnológicos mucho más costosos que los del laboratorio. El INI se enfrentaba a tener que hacerse con saberes que se hallaban en las fases más complejas y gravosas de los ciclos de vida de las tecnologías implicadas. Tenía que adquirir conocimientos que estaban en un mercado, el de la transferencia de tecnología entre empresas y agencias gubernamentales, con altas barreras de entrada, y donde los productos científicos y tecnológicos tenían costes altos.

El proceso de "revalorización» solía quebrarse en esta transición, porque no había suficientes tecnólogos adecuadamente formados como para conseguir producir industrialmente a bajo precio, unos productos que en el mercado internacional tenían sustitutos mucho más baratos. Sólo desde la lógica militar e ingenieril de la movilización industrial tenía coherencia llevar a cabo aquellas experiencias. El problema era que la aplicación de tecnología de laboratorio no podía aumentar la valía de un residuo o desperdicio en un plazo económicamente aceptable, $o$, lo que viene a ser lo mismo, los costes de superar la fase semiindustrial y entrar en la industrial suponían la principal barrera para pasar de la "revalorización" a la sustitución de importaciones.

Los responsables de la política tecnológica e industrial no sólo desestimaron el valor en el mercado internacional de productos similares 


\section{El Patronato «Juan de la Cierva» (1939-1960)}

a los que se obtenían con la "revalorización", bajo la excusa de que en situación de guerra no tendrían problema de abastecimiento, sino también el coste de oportunidad de gastar unos fondos exiguos en construir unas instalaciones inútiles - como por ejemplo las de Puertollano para destilar pizarras bituminosas-, y de hacer trabajar a unos tecnólogos escasos en unas tareas innecesarias frente a la opción de importar las verdaderas materias primas y productos intermedios.

Sin embargo, no podemos decir que aquellos hacedores de la política económica y científica no tuvieran precedentes. Una larga tradición de esfuerzos en investigación desde antes de la guerra civil por parte de los militares, algunos industriales y centros de investigación como el IQS, habían intentado "revalorizar» el carbón nacional. Lo que sucedió en 1946 fue que la tentativa del INI se basó en implicar a la H.A. Brassert \& Co. Ltd. para que ésta cediese la tecnología necesaria, pero H.A. Brassert \& Co. Ltd. señaló que el único camino posible para solucionar el tema, era montar un horno semiindustrial para experimentar con los carbones nacionales ${ }^{20}$. La respuesta del INI fue la habitual, potenciar la investigación en el PJC y poner un hombre del INI al frente. El PJC creó nominalmente en 1946 el I Carbón, siguiendo las indicaciones de la CTE de Combustibles del PJC dirigida por J. Planell, y un año más tarde el INI colocó a F. Pintado Fe de director del mismo ${ }^{21}$. Pintado $\mathrm{Fe}$ intentó "revalorizar» el carbón durante los siguientes tres años ${ }^{22}$. Se llegó así a 1950, momento en el que se inauguró en La Corredoría (Oviedo) el I Carbón, coincidiendo con la creación de ENSIDESA, para la que el recién nacido I Carbón emitió un informe sobre las posibilidades de abastecimiento de coque basándose en carbones indígenas. En el informe se proponía el montaje de una instalación semiindustrial de obtención de coque - dependiente de ENSIDESA - en los mismos términos que indicara H.A. Brassert \& Co. Ltd. ${ }^{23}$. En 1953 el Gobierno, a petición del INI, autorizó a éste para que pudiera conceder "un préstamo, de suficiente importancia, para acelerar el ritmo de tales obras, principalmente las relativas a las plantas experimentales de lavado, mezclas y coquificación, con todas sus instalaciones accesorias. (...) el Consejo Técnico-Administrativo del IN Combustible, ha acordado que, una vez otorgado el mencionado préstamo por el INI, se pongan en inmediata ejecución las obras del apartadero de ferrocarril y las de la planta experimental de coquificación" ${ }^{24}$. La escala del gasto en los experimentos se disparaba, pero se esperaba que poniendo fuertes aranceles al coque de importación y subvencionado el nacional el problema se subsanaría. De esta forma cualquier preocupación por el coste de oportunidad quedaba relegada 
gracias a una política arancelaria que favoreciese el esfuerzo tecnológico realizado.

Junto a la obsesión por "revalorizar» el carbón también se encontraba la de dar con un sustituto a la chatarra. En 1948 el problema de la falta de chatarra había hecho variar la opinión de los técnicos e industriales españoles en favor de experimentar con procedimientos, como el Renn-Krupp, que evitase la dependencia de la importación de chatarra ${ }^{25}$. El procedimiento Renn-Krupp servía para mejorar las prestaciones de minerales de hierro de baja calidad con el objeto de conseguir un producto de características similares a la chatarra. Para ponerlo en marcha en España se escogió al IH Acero, que inicialmente funcionó más como un centro de reuniones de los empresarios interesados en temas de investigación, que como un instituto de investigación ${ }^{26}$. No fue hasta 1955 cuando consiguió unos locales fijos, y aun así, tuvo que esperar hasta finales de los años cincuenta para que, con un préstamo del INI, pudiera contar con un edificio -en el barrio de Legazpi (Madrid), muy cerca del CI ENCASO- apropiado para sus análisis ${ }^{27}$.

Con la "revalorización" de los residuos agrícolas pasó lo mismo que con el coque y el procedimiento Renn-Krupp. Desde las cáscaras de naranjas hasta las cañas del maíz toda suerte de desperdicios fueron analizados en las instalaciones del CI ENCASO, del DQ Vegetal y de la S Fermentaciones con el objetivo de convertirlos en fermentos, aceites y ácidos que sustituyeran la importación de productos mejores y más baratos. En este caso se llegó a crear en 1952 la Empresa Nacional de Industrialización de Residuos Agrícolas SA (ENIRA), cuyo presupuesto acumulado supuso varios cientos de millones de pts. y nunca produjo nada ${ }^{28}$. ENIRA había nacido tecnológicamente en el PJC, a raíz de detectar la oportunidad tecnológica de "revalorizar" subproductos agrícolas, pero el INI fue incapaz de convertirla en una empresa industrial, sencillamente porque nadie, ni tampoco el INI, necesitaba unos aceites, fermentos y ácidos peores y más caros que los importados.

La historia de la "revalorización" de la pizarras bituminosas y de las piritas vuelve a repetir la misma pauta. En el primer caso se llegó a producir una tonelada de lubricantes después de varios años de experimentación semiindustrial para luego abandonar las instalaciones y todo proyecto de destilación de pizarras. En el segundo, los proyectos para montar los hornos de tostación de piritas que se necesitaban, se discutieron e incluso hubo dotaciones presupuestarias para su compra, pero nada más ${ }^{29}$. 
El Patronato «Juan de la Cierva» (1939-1960)

El objetivo de la "revalorización" había resultado fallido en todos sus intentos. La pretensión de que gracias a los trabajos de los centros de investigación se podrían concebir empresas, como si éstas sólo necesitasen una oportunidad tecnológica para funcionar, fue lo que estuvo detrás de los sucesos como el de ENIRA ${ }^{30}$.

La otra gran función que cumplieron los institutos del PJC para el INI, tal y como se ha indicado, fue la de informar a éste del "estado del arte" en las tecnologías que necesitaba conocer para poner en marcha sus empresas, así como de indagar las condiciones de las empresas privadas al respecto. Los costes de aquella información eran muy reducidos para el INI. Cuando las averiguaciones terminaban el centro de investigación seguía siendo mantenido por el PJC, aunque sin contenidos ni objetivos definidos. El INI lo dejaba morir a todos los efectos. De esta manera el INI se aprovechaba del capital humano y no necesitaba contratarlo ni crear los centros de investigación por su cuenta y riesgo exclusivos. A la vez el INI se servía del PJC para vigilar las iniciativas de las empresas privadas. Así por ejemplo, el I Carbón, sin ser un centro del INI en realidad actuaba como tal, y desde su ambigüedad le permitía al INI conocer la situación tecnológica de las empresas privadas mineras y siderúrgicas, en el punto gordiano de la utilización del coque, al mismo tiempo que los estudios previos a la formación de ENSIDESA eran en parte "subvencionados" a través de las exacciones que las industrias pagaban. El IH Acero complementaba la labor del I Carbón gracias a que reunía a un buen número de empresas -Echevarría SA, Sociedad Española de Construcción Naval, José María Quijano, Sociedad Metalúrgica Duro Felguera, Altos Hornos de Vizcaya, Fábrica de Mieres, Compañía Anónima Basconia, A. Pedro de Elgoibar, Torras HC, Unión Cerrajera, Nueva Montaña, Material y Construcciones, Altos Hornos de Cataluña, Siderúrgica Asturiana y SA Vers- que sufrían las exacciones fiscales correspondientes y participaban en unos proyectos de investigación que en última instancia se correspondían con los planes del INI ${ }^{31}$.

Con el tiempo la labor del PJC, por culpa de este tipo de actuación, quedó en entredicho ante las empresas privadas. Es cierto que en los consejos de los institutos participaron representantes de la industria privada con el objetivo de que señalaran problemas e indicaran pautas de investigación, pero Suanzes volvió a imponer su principio rector del «interés nacional» que debía emanar desde lo público y ser admitido por lo privado ${ }^{32}$.

Al restar el protagonismo a la empresas privadas en la dirección de los institutos estos dejaban de tener sentido como transmisores y 
divulgadores de las técnicas, ya que no existía confianza sobre la virtud de la dirección que tomaba la información, puesto que acababa beneficiando más a las empresas públicas. Esto era evidente cuando pasados los primeros dos o tres años resultaba que los problemas que se estaban estudiando eran los mismos que, desde el lado industrial, interesaban al INI. Así por ejemplo, el IH Acero no podía funcionar bajo el modelo de asociación de investigación que aparecía en sus estatutos, puesto que entre 1946 y 1950 estudió los problemas científicos y tecnológicos a los que con posterioridad se enfrentaría, ahora ya desde el plano industrial, ENSIDESA. De hecho cuando ésta se creó en 1950 parte del personal del PJC pasó a ella con A. Fernández Ávila al frente.

$\mathrm{El}$ esquema de funcionamiento del PJC en síntesis se puede resumir de la siguiente manera. Los institutos importantes del PJC por su presupuesto, instalaciones e investigadores eran los que tenían a su disposición las exacciones fiscales fijadas en 1946 según los planes de Suanzes, es decir IH Acero, I Combustible -y dentro de él el I Carbón-, ITC Edificación e I Soldadura ${ }^{33}$. De ellos, los tres primeros estaban íntimamente relacionados con el INI. Las exacciones respaldaban los créditos que el INI otorgaba para la edificación de las instalaciones. De esta manera el INI se aseguraba el interés de la inversión en la parte de la I+D correspondiente a la edificación ${ }^{34}$. Más tarde el INI se servía de estos institutos para alcanzar sus objetivos de "revalorizar" subproductos, conocer el "estado del arte" de las tecnologías que le interesaban y de extraer información de los planes de las empresas privadas. Pero, a mediados de los años cincuenta los proyectos de "revalorización" no habían pasado a la fase industrial y la industria privada recelaba de la virtud del PJC y no participaba de buena gana en su mantenimiento ni en sus proyectos, entonces ¿qué valor tenía para el INI mantener las relaciones con el PJC? Informar del "estado del arte" de parte de las tecnologías que le interesaban al INI, como el frío industrial, la calcinación de piritas o la energía eólica ${ }^{35}$.

Desde 1953 la Dirección Técnica del INI quería deslindar al INI del PJC, porque éste no servía como fuente de tecnología, ya que sólo era capaz de informarle de la parte más básica, es decir, la del "estado del arte». El intento de Suanzes de hacer crecer al INI y al PJC a la vez y plenamente conectados se había venido abajo por la incapacidad del PJC de ofrecer al INI la cantidad de tecnología que éste requería. Ahora bien, desde la perspectiva del PJC el fracaso del crecimiento al unísono de las dos instituciones radicaba en el INI, porque éste era incompetente a la hora de dar el salto de las investigaciones de 
laboratorio a las de escala industrial en los temas prioritarios relacionados con la "revalorización".

La frustración mutua debió de ser intensa, e hizo desistir, durante muchos años, tanto a unos como a otros, de conseguir industrias con bases tecnológicas en la investigación y el desarrollo propios. Tal y como predijo Suanzes los dos mundos, el de la industria y el de la investigación, se fueron separando. El INI viró su política hacia los contratos de transferencia de tecnología con suministradores extranjeros y el PJC se concentró en sus propios proyectos y en los servicios a pequeñas industrias, que no presentaban problemas de escala ${ }^{36}$. Pero el daño ya estaba hecho. Quedó, tanto en la industria privada como pública, un poso permanente de incredulidad con respecto a la investigación aplicada nacional como método para acortar distancias en relación a los países más industrializados. Si nuestra preferencia por la transferencia de tecnología como fuente del cambio tecnológico de la industria es tan acusada, en la actualidad somos uno de los primeros países del mundo que más se gasta en importar tecnología tanto en valores absolutos como en relación al número de habitantes, se explica no sólo por la falta de un mercado amplio de tecnólogos, sino también por lo desacertado de la política científica y tecnológica llevada a cabo en los años cuarenta y cincuenta del presente siglo ${ }^{37}$.

\section{Apéndice I: siglas}

BMI: $\quad$ Battelle Memorial Institute

CAICYT: Comisión Asesora de Investigación Científica y Técnica

CE Eólica: $\quad$ Comisión de Energía Eólica

CE Frío: Centro Experimental del Frío

CETA: Centro de Estudios Técnicos de la Automoción

CETE: $\quad$ Centro de Estudios Técnicos de la Electricidad

CETME: Centro de Estudios Técnicos de Material Especial

CETO: Centro de Estudios Técnicos de Obras

CI Documentación: Centro de Información y Documentación

CI ENCASO: Centro de Investigación de la Empresa Nacional «Calvo Sotelon de Combustibles Líquidos y Lubricantes

CIV: $\quad$ Centro de Investigaciones Vinícolas 
$\mathrm{CP}$ :

Comisión Permanente de la Junta de Gobierno del PJC

CSIC: $\quad$ Consejo Superior de Investigaciones Científicas

CTA:

Consejo Técnico Asesor del Patronato "Juan de la Cierva"

CTE: $\quad$ Comisión Técnica Especializada (perteneciente al PJC)

D Óptica: Departamento de Óptica Técnica

D Plásticos: Departamento de Plásticos

D Silicatos: Departamento de Silicatos

DII Piritas: División de Investigación Industrial de «Piritas Españolas S.A."

DQ Vegetal: Departamento de Química Vegetal

DT:

Dirección Técnica del Instituto Nacional de Industria

ENCASO: $\quad$ Empresa Nacional "Calvo Sotelo" de Combustibles Líquidos y Lubricantes

ENIRA: $\quad$ Empresa Nacional de Industrialización de Residuos Agrícolas

ENOSA: $\quad$ Empresa Nacional de Óptica S.A.

ENSIDESA: Empresa Nacional Siderúrgica S.A.

FNICER: $\quad$ Fundación Nacional para Investigaciones Científicas y Ensayos de Reformas

I Carbón: Instituto del Carbón

I Forestal: Instituto Forestal de Investigaciones y Experiencias

I Soldadura: Instituto de la Soldadura

IE Grasa: Instituto Especial de la Grasa

II Pesqueras: Instituto de Investigaciones Pesqueras

IH Acero: Instituto del Hierro y del Acero

IN Combustible: Instituto Nacional del Combustible

IN Electrónica: Instituto Nacional de Electrónica

IIT Barcelona: Instituto de Investigaciones Técnicas de Barcelona

ILT Quevedo: Instituto "Leonardo Torres Quevedo" de Física Aplicada

INI: Instituto Nacional de Industria 


\section{El Patronato «Juan de la Cierva» (1939-1960)}

$\begin{array}{ll}\text { INR Trabajo: } & \text { Instituto Nacional de Racionalización del Trabajo } \\ \text { ITC Edificación: } & \text { Instituto Técnico de la Construcción y la Edificación } \\ \text { IQA Oviedo: } & \text { Instituto de Química Aplicada de Oviedo } \\ \text { IQS: } & \text { Instituto Químico de Sarrià } \\ \text { INTA: } & \text { Instituto Nacional de Técnica Aerospacial } \\ \text { JAE: } & \text { Junta para Ampliación de Estudios } \\ \text { JEN: } & \text { Junta de Energía Nuclear } \\ \text { JG: } & \text { Junta de Gobierno del Patronato "Juan de la Cierva" } \\ \text { LITIEMA: } & \text { Laboratorio y Taller de Investigaciones del Estado Ma- } \\ & \text { yor de la Armada } \\ \text { Laffón-Selgás: } & \text { Laboratorio de Investigaciones de Electro-Acústica "Laf- } \\ & \text { fón-Selgás" } \\ \text { PJC: } & \text { Patronato "Juan de la Cierva" de Investigación Técnica } \\ \text { S Fermentaciones: } & \text { Sección de Fermentaciones Industriales } \\ \text { T Subvencionados: } & \text { Trabajos Subvencionados }\end{array}$

\section{Apéndice II: citación de las fuentes}

Libros de las Actas de la Junta de Gobierno y de la Comisión Permanente. Estos libros son anuales con la excepción de los dos primeros años, 1946 y 1947, que se presentan en un sólo tomo. Existen dos colecciones. Una en el departamento de Actas del CSIC -accesible a la consulta pública previa autorización-y otra en el Archivo de la Ciencia de la Universidad Autónoma de Madrid. Esta fuente se cita de la siguiente manera: PJC JG 17-7-53, que se lee Patronato "Juan de la Cierva" Junta de Gobierno del día diecisiete de julio del año 1953, y PJC CP 12-2-54, que se lee Patronato "Juan de la Cierva" Comisión Permanente del día doce de febrero del año 1954.

La fuente principal utilizada dentro del archivo del INI han sido los legajos pertenecientes a la Dirección Técnica que abarcan desde 1945 hasta 1970. La cita de esta fuente se realiza normalmente por expedientes de la siguiente manera:

INI, sección (E Estafeta V Vergara), legajo, signatura, número del legajo en el anaquel, carpeta, expediente, y fecha. Ejemplo: INI, E, legajo 004-0, 9, exp. 32 (1-1-1945), que se lee de la siguiente manera: Archivo del INI, sección Estafeta, Legajo correspondiente al tema de 
Patentes y Marcas, que está situado el noveno empezando por la izquierda en el anaquel correspondiente a dicha signatura, expediente número 32 cuya fecha es el uno de enero de 1945.

\section{Notas}

1 El caso al que nos referimos fue el de AVSA, una empresa creada por una parte de los investigadores de la Sección de Alto Vacío del ILT Quevedo, quienes pagaban determinados cánones al PJC por la utilización de algunas patentes del ILT Quevedo -López García (1994a), pp. 266-.

2 Hoffmann (1958).

3 OCDE-CDTI (1976).

4 Las principales líneas de investigación de esta sección en 1952 eran el aprovechamiento de materias primas secundarias y residuos (triturado de algarroba para obtener zumos azucarados aprovechables en fermentaciones), y los estudios enológicos (planta piloto para mejorar la desulfitación del mosto) —CSIC (1953)—.

5 CSIC (1954), p. 108-109.

6 CSIC (1956), p. 113.

7 PJC CP 24-5-48, CP 4-2-49, CP 21-2-49, CSIC (1953) y (1956), pp. 155 y 156.

8 La línea de investigación que más potenció estos trabajos fue el estudio de edificaciones modestas. En 1951 se estimó que se necesitaban 50.000 viviendas nuevas al año, lo que suponía una inversión de 3.000 millones de pts. anualmente. Dado que la diferencia entre poder adquisitivo y costes era muy elevada, se necesitaban ahorros en la construcción como vía para ajustar las necesidades a las inversiones. Para ello el ITC Edificación promovió la industrialización de la edificación como la única opción "posible y capaz de permitir que el ciclo producción, venta y arrendamiento sea cerrado económicamente y dé a los medios de producción los elementos necesarios para proseguir su marcha sin intervenciones exteriores". CSIC (1952), p. 55.

9 CSIC (1952), pp. 55-59.

10 Los resultados conseguidos en este tema superan los previstos en el plan de trabajo. Puede asegurarse que el Instituto marcha a la cabeza en las investigaciones mundiales sobre este tema, en lo que respecta a su aplicación a la Química de la Grasa; y reflejo de este hecho son las numerosísimas peticiones que se vienen recibiendo de copias de nuestras publicaciones sobre esta cuestión. CSIC (1953), p. 67.

Los logros fueron: un método para la preparación de aductos de urea basado en la flotaciọ́n en disolventes, el descubrimiento de que la urea forma aductos con los mono y diglicéridos - publicado en la revista alemana Fette und Seifen-, la preparación y análisis de nuevos compuestos, la separación de las mezclas de ácidos grasos y resínicos -importante para la industria del papel-, la diferenciación de dos isómeros y la creación de una técnica nueva análoga a la cromatográfica, para estudiar el fraccionamiento de ácidos grasos con un grado de separación superior al de otras técnicas, que se usaban en aquellos años para analizar productos químicos CSIC (1953), p. 68 .

11 Los aspectos teóricos de este comportamiento se explican en López García (1994a), cap. I. 


\section{El Patronato «Juan de la Cierva» (1939-1960)}

12 Posiblemente su conexión procedía de los proyectos de movilización industrial formalizados por el ejército con ocasión de la I Guerra Mundial —San Román (1993) y (1995)-.

13 CSIC (1947)

14 PJC CP 20-1-47. V. Gómez Aranda (director de la sección de Zaragoza del I Combustible) M. Méndez Vigo y González Hontoria formaban además la representación del INI en las Asambleas Generales del IH Acero - INI, E (C-2), legajo 051, 4, exp. 84 (23-10-48)-.

15 PJC CP 26-3-54.

16 El CE Frío se creó en 1950, a partir de los estudios que el INI había encargado a R. Beltrán para desarrollar una red de frío industrial. Beltrán intentó dotarlo de medios y contenidos pero el fracaso fue notable. Permaneció inactivo hasta 1957, año en el que fue sustituido R. Beltrán por M. Estasa, quien también procedía del Departamento de Industrias de la Alimentación de la DT del INI. Hasta 1958 no se iniciaron las investigaciones aplicadas por la falta de instalaciones apropiadas y por la imposibilidad de la Administración para montar un sistema de exacciones fiscales sobre las empresas relacionadas con el frío industrial -PJC CP 23-4-54, INI, E (D2), legajo 051 DT, 3, exp. 63 (15-2-52) y INI, E (D2), legajo 051 DT, 4, exp. 274 (11-8-52)-. Estasa defendió que la única manera de sacar adelante el CE Frío pasaba por el apoyo económico mayoritario del INI sin pensar en las exacciones. Por fin en 1958 consiguió una subvención anual del INI de medio millón de pts., que permitió subsistir al centro pero no crear tecnología -PJC CP 16-11-57 y CP 28-2-58-. La clave del fracaso del CE Frío estuvo en el escaso interés que el INI tenía por la industria del frío, en la cual hizo intervenciones momentáneas más motivadas por las cuestiones políticas coyunturales que por las económicas - Gómez Mendoza (1995)—.

17 Decreto del Ministerio de Educación Nacional del 14 octubre de 1942.

18 Acta de la reunión del Consejo Técnico Químico del INI, sesión del 13-2-1943, Actas, Consejos Técnicos, INI, 1943.

19 Boletín Oficial del Estado, núm. 196, 15-7-1945. Se fijó 1946 como el año de la reorganización del Patronato, que sería ejecutada por Fernández Ávila, Lora Tamayo y el propio Suanzes. También debió intervenir en la reorganización J. Sirvent, quien era, aparte de Secretario del INI, consejero del ILT Quevedo, cargo al que renunciaría en 1950 -PJC CP 18-1-50-.

20 INI, E, legajo 051, 16, exp. 268 (30-9-46).

21 Pintado $\mathrm{Fe}$ era un hombre joven, que había terminado la ingeniería de minas en 1940, posteriormente había trabajado en la Oficina Técnica y de Proyectos de Duro-Felguera hasta llegar a ser jefe de las minas Santa Ana. En 1943 el INI le contrató para el Departamento de Carbones de la DT. -PJC CP 3-3-47-.

22 La primera misión de Pintado Fe fue enterarse del "estado del arte». En 1947 inició un viaje que le llevó a las cuencas de hulla de Francia, luego a las minas de carbón de Bélgica y Holanda y, por último, a los laboratorios industriales de la minería del Reino Unido. Durante 1948 y 1949 Pintado Fe se dedicó a la obtención de información extranjera para aplicarla a las instalaciones que se estaban proyectando para el I Carbón. Estableció contactos institucionales, adquirió bibliografia y, sobre todo, entró en relaciones con las empresas extranjeras capaces de proyectar o construir las instalaciones semiindustriales previstas para el instituto - CSIC (1948b) y CSIC (1949), p. 71-

23 Mientras se aprobaba esta idea el I Carbón se concentró en dos tipos de investigaciones: el estudio a pie de mina - Hullera de Reinosa SA, Minero Industrial 
Pirenáica SA y Minas de La Reunión - de la lavabilidad de los carbones para eliminar las cenizas que impedían la coquificación, y la obtención de mezclas de carbones nacionales idóneas para su coquificación. Esta última era un encargo de ENSIDESA y la Sociedad Metalúrgica Duro-Felguera - CSIC (1953)—.

24 CSIC (1954) pp. 43 y 44.

25 INI, E (C-2), legajo 051, 2, exp. 14 (8-3-48).

26 En el Consejo de Administración del IH Acero se sentaban con Plana Sancho los representantes de la Dirección General de Industria y Material del Ministerio del Ejército, de Altos Hornos de Vizcaya, de Duro-Felguera, de la Sociedad Española de Construcción Naval, de la Sociedad Anónima Echevarría, de Unión Cerrajera de Mondragón, del INTA y de las escuelas de ingeniería -PJC CP 25-2-47-. Entre 1947 y 1955 se comportó como un instituto itinerante que se apoyaba en el INTA, en el IIT Barcelona y en los laboratorios privados, para llevar a cabo sus estudios, que normalmente consistían en la repetición y copia de experiencias ya conocidas en el extranjero. Durante esta primera época lo más importante que hacía el IH Acero eran sus Asambleas Generales una vez al año, donde se reunían representantes de las industrias nacionales y de centros gubernamentales extranjeros. Con el tiempo los temas sobre los que se discutía y proponian nuevas investigaciones pasaron a ser muy parecidos a los que interesaban al INI: el estudio de la aplicación en España de los procedimientos de fabricación de esponja de hierro Höganas y Wiberg, productos siderúrgicos que se conseguían por los procesos Renn-Krupp y Basset, fabricación de hornos eléctricos de cuba baja, creación en España de instalaciones para sinterización, estudio de los procedimientos de metalurgia rápida, problemas de laminación y estudio de las fundiciones especiales de alta calidad.

27 En 1956 el INI empezó los trámites para conceder al IH Acero un préstamo por treinta millones de pts. para la construcción de su sede - PJC CP 21-9-56- El edificio sería diseñado por el Battelle Memorial Institute e inaugurado en 1959 durante un congreso internacional de fundición -PJC CP 8-5-57 y JG 26-11-59-.

28 La DT del INI informó favorablemente del proyecto del CI ENCASO de crear una fábrica en Sevilla donde se tratasen diversas cantidades de residuos de orujillo, maíz y algodón. El presupuesto de la fábrica se cifró en 207 millones de pts. El objetivo era conseguir cetonas carburantes y levaduras de piensos - INI, E (D2), legajo 051 DT, 2, exp. 319 (10-7--51) y Buesa (1982), pp. 275 y 276-. M. Buesa señala que la experiencia de ENIRA constituyó un fracaso tecnológico, de manera que su programa inicial de construcción de cinco plantas de producción nunca llegó a completarse. De hecho sólo pudo montarse la factoría de Linares, que no logró entrar en funcionamiento normal, por lo que en 1971 se disolvió la empresa.

29 Gómez Mendoza (1994).

30 Sin embargo, cuando el objetivo no era la "revalorización" las cosas marchaban mejor, como se demostró en ENOSA (Empresa Nacional de Óptica S.A.). ENOSA nació en 1949 del Departamento de Óptica Técnica del Instituto de Óptica "Daza Valdés" del CSIC. Desde 1946 el PJC subvencionaba las investigaciones en dicho instituto, interesado por el hecho de que el antiguo jefe de laboratorios de la Carl Zeiss, F. Weidert, pudiera poner en marcha un proyecto de industria óptica en España -PJC CP 5-10-49-

O. Navascués aprovechó en 1953 la presencia de Weidert en ENOSA para cerrar un contrato de asistencia técnica con la Carl Zeiss, que le permitió afrontar la fabricación industrial de productos de óptica. 


\section{El Patronato «Juan de la Cierva» (1939-1960)}

ENOSA cuenta con el asesoramiento y ayuda técnica de la famosa Fundación Carl Zeiss que se compromete mediante contrato firmado entre el INI y dicha Fundación a poner a disposición de ENOSA sus procedimientos y métodos de fabricación y también a venderle las patentes de todos los instrumentos que produzca Zeiss en sus nuevas fábricas de Oberkoken. (...) En virtud del contrato con Zeiss llegaron a España los ingenieros Diplomados Sres. Upmann y Schreiber para asesorar a la Dirección de ENOSA en la dirección y planificación de la misma - INI, E (D2), legajo 051 DT, 5, exp. 49 (28-1-53)-.

La empresa fue creciendo gracias a contratos con la Administración y a la absorción, en 1957, de los talleres, personal y contratos del ILT Quevedo -PJC CP 26-2-57, CP 23-12-57 y CP 31-1-58-.

31 CSIC (1948b). Otros institutos también contaron con el apoyo inicial de las industrias de su sector. El IIT Barcelona tuvo como colaboradores a la Compañía General de Asfaltos y Portland "Asland", a Sucesora de Aceros Eléctricos SA, a Talleres Unión, a Construcciones Electromecánicas Abril y a la Maquinista Terrestre y Marítima -CSIC (1948b), p. 137 y (1949), p. 150-. Por su parte el IE Grasa conectó con las siguientes empresas para que le facilitaran sus centros de investigación en un primer momento: Centro de Estudios del Tabaco de Santiponce, Unión Química del Norte de España, CAMPSA, Casa Vidaurrieta y Establecimientos Girod - CSIC (1948b) -

32 "Al servicio del superior interés de nuestra economía, deseamos que nuestros institutos (...) puedan llegar a señalar orientaciones y directrices de carácter técnico a las industrias, y que recibiendo de ellas, por otra parte, iniciativas y sugerencias, puedan hacer llegar hasta las más modestas empresas el fruto de sus trabajos". Discurso de Suanzes en la VIII reunión plenaria del CSIC de 1947 (CSIC (1948a), p. 92 -

33 En segundo término estaban los que tenían asegurado la participación de algún organismo estatal en su presupuesto, como en el caso del IN Electrónica con respecto a los ministerios de los ejércitos.

34 Los gastos de edificación entran dentro del cómputo de la I+D según los organismos internacionales encargados de su medición. Véase el razonamiento de su inclusión en OCDE-CDTI (1976).

$35 \mathrm{El}$ origen de las investigaciones en energía eólica estuvo en el Departamento de Electricidad de la DT del INI, que en 1949 inició un proyecto para su aprovechamiento. En 1951 creó la CE Eólica coordinándola con el PJC -PJC CP 4-12-51-. Durante 1952 se dotó a la CE Eólica de instalaciones y personal, y M. Ballester, recientemente nombrado secretario de la CE É́lica, propuso entrar en el consorcio Enfield Cables Ltd, De Havilland Propellers Ltd y English Electric Co. que era el grupo más activo en este campo industrial - INI, E, legajo 004-0, 6, carp. 1, exp. 51 (oct.- 53)—. Después de dos años de trabajos la CE Eólica se dio cuenta de que la tecnología de los generadores de energía eléctrica por eólicas estaba en una fase de estancamiento. Ante este panorama la CE Eólica se transformó en una especie de oficina para el estudio de energías no convencionales - INI, E (D2), legajo 051 DT, 13, exp. 776 (26-11-55) y PJC CP 9-11-55-.

36 La similitud de esta situación con lo que sucedió en el siglo XVIII con la botánica es notable. Al final en ambos casos queda la sensación de una ilusión quebrada, si bien una de carácter ilustrado -Puerto Sarmiento (1988) - y la otra nacionalista -Buesa (1982)-.

37 Con referencia a nuestro gasto en transferencia de tecnología véase OCDE (1986), (1987) y López García (1992). 


\section{Bibliografía}

ALBAREDA HERRERA, J.M. (1951), Consideraciones sobre la investigación cientifica. CSIC, Madrid.

APOKIN, I.A. y CHAPOVSKI, A.Z. (1991), "The origins of the first scientific center for automation". History and Technology, vol. 8, núm. 2, pp. 133-138.

Atienza, E. (1994), El General Herrera. Aeronáutica, milicia y politica en la España Contemporánea. AENA, Madrid.

AUSEJO, E. (1993), Por la ciencia y por la patria: la institucionalización científica en España en el primer tercio del siglo XX. La Asociación Española para el Progreso de las Ciencias. Siglo XXI, Madrid.

Ballestero, A. (1993), Juan Antonio Suanzes 1891-1977. La política industrial de la posguerra. LID, Madrid.

Braña, J., Buesa, M. y Molero, J. (1984), El Estado y el cambio tecnológico en la industrialización tardia. Un análisis del caso español. FCE, México.

BUESA, M. (1982), El Estado en el proceso de industrialización: contribución al estudio de la política industrial española en el período 1939-1963. (Tesis doctoral), UCM, Madrid.

Camarasa, J.M., Marti, J. y Roca, A. (1992), La Mirada dels Científics. Fent Ciència a Catalunya, (Catálogo de la exposición del mismo nombre). Departament de Cultura - Generalitat de Catalunya, Barcelona.

CAMON, L. (1978), "Una aproximación al Consejo Superior de Investigaciones Científicas (C.S.I.C.)", en Camón,L., Cid, F., Garrabou, R., Lacalle, D., Marcos, J., Narbona, P., Ponsa, M., Quintanilla, M.A., Ras, E. y Rodríguez, E., Jornadas de historia y filosofia de las ciencias y las técnicas. CXXV aniversario de la Escuela de Ingenieros Industriales de Barcelona (1851-1976). E.T.S.E.I., Barcelona.

CASADOde OTAOLA, S. "Juan Negrín y la Residencia de Estudiantes", EL PAÍS, (sociedad), 29 de diciembre, año XVII, núm. 5.725, p. 22.

CATALaN, J. (1990). "Capitales modestos y dinamismo industrial: orígenes del sistema de fábrica en los valles guipuzcoanos, 1841-1918", en Nadal y Carreras (Dirección y Coordinación), Pautas regionales de la industrialización española (siglos XIX y $X X)$. Ariel, Barcelona. pp. 125-155.

- (1993), Fábrica y franquismo, 1939-1958. El modelo español de desarrollo en el marco de las economías del sur de Europa. Tesis Doctoral (edición microfotográfica), Universitat Autònoma de Barcelona, Barcelona.

Comin, F. (1985), "La evolución del Gasto del Estado en España, 1901-1972: Contrastación de dos teorías", en Martín Aceña, P. y Prados de la Escosura, L. (eds.)(1985), La nueva historia económica en España. Tecnos, Madrid. pp. 317-341.

Consejo Superior de Investigaciones Científicas CSIC (1942), Memoria de la Secretaría General 1940-1941. CSIC, Madrid.

- (1943), Memoria de la Secretaría General 1942. CSIC, Madrid.

- (1944), Memoria de la Secretaría General 1943. CSIC, Madrid.

- (1945), Memoria de la Secretaría General 1944. CSIC, Madrid.

- (1946), Memoria de la Secretaría General. Año 1945. CSIC, Madrid.

- (1947), Memoria de las actividades desarrolladas por el Patronato "Juan de la Cierva Codorniu" año 1946. CSIC, Madrid.

- (1948a), Memoria de la Secretaría General. Año 1946-47. CSIC, Madrid. 


\section{El Patronato «Juan de la Cierva» (1939-1960)}

- (1948b), Memoria de las actividades desarrolladas por el Patronato "Juan de la Cierva Codorniu" año 1947. CSIC, Madrid.

- (1949), Memoria de las actividades desarrolladas por el Patronato "Juan de la Cierva Codorniu» año 1948. CSIC, Madrid.

- (1949b), Reglamento del Patronato "Juan de la Cierva" de Investigación Técnica. CSIC, Madrid.

-(1952), Memorias de las Actividades desarrolladas por el Patronato "Juan de la Cierva" de Investigación Técnica, año 1951. CSIC, Madrid.

- (1953), Memorias de las Actividades desarrolladas por el Patronato "Juan de la Cierva" de Investigación Técnica, año 1952. CSIC, Madrid.

- (1954), Memorias de las Actividades desarrolladas por el Patronato "Juan de la Cierva" de Investigación Técnica, año 1953. CSIC, Madrid.

- (1955), Memorias de las Actividades desarrolladas por el Patronato "Juan de la Cierva" de Investigación Técnica, año 1954. CSIC, Madrid.

- (1956), Memorias de las Actividades desarrolladas por el Patronato "Juan de la Cierva" de Investigación Técnica, año 1955. CSIC, Madrid.

CRIADO, E. (1990), "El sistema científico-técnico en España”, en Fundación $1^{\circ}$ de mayo, Ciencia y cambio tecnológico en España. Fundación $1^{\circ}$ de Mayo - MEC - MINER, Madrid. pp. 105-152.

DiPUTACION DE BARCELONA (1916), Guia de les institucions científiques $i$ d'ensenyança. Publicacions del Cosell de Pedagogia, Barcelona.

FNICER (1935), Memorias correspondientes a los años 1932, 1933 y 1934 de la Fun. dación Nacional para Investigaciones Cientificas y Ensayos de Reformas. FNICER, Madrid.

FreEMAN, C. (1975), La teoría económica de la innovación industrial. Alianza Editorial, Madrid.

FriAS, J. (1988), "La investigación tecnológica para su 'despegue' definitivo". Nuevo Siglo, núm. 6, diciembre, pp. 83-88.

FUKASAKU, Y. (1992), "Origins of Japanese industrial research: Prewar government policy and in-house research at Mitsubishi Nagasaki Shipyard». Research Policy, vol. 21, pp. 197-213.

GALI, A. (1981-1987), Història de les institucions $i$ del moviment cultural a Catalunya (1900-1936). Fundación A. Galí, Barcelona.

Garcia Camarero, Ernesto y Garcia Camarero, Enrique. (1970), La polémica de la ciencia española. Alianza Editorial, Madrid.

Garcia Perez, R. (1994), Franquismo y Tercer Reich. CIS, Madrid.

Garcia SANTESMASES, J. (1980), Obra e inventos de Torres Quevedo. Instituto de España, Madrid.

Garma, S. y Sanchez Ron, J.M. (1989), La Universidad de Madrid y el Consejo Superior de Investigaciones Científicas. ALFOZ. Núm. 66-67, págs. 59-77.

GLICK, T.F. (1986), Einstein y los Españoles. Ciencia y sociedad en la España de Entreguerras. Alianza Editorial, Madrid.

- (1988), La Fundación Rockefeller en España: Augustus Trowbridge y las negociaciones para el Instituto Nacional de Física y Química, 1923-1927, en Sánchez Ron, J. M. (coordinador) (1988), 1907-1987 La Junta para Ampliación de Estudios e Investigaciones Científicas 80 años después. Madrid, CSIC, pp. 281-300.

GLick, T.F. y SANCHEZ Ron, J.M. (ed) (1988), Memorias de Emilio Herrera. UAM, Madrid. 
Goldis, F. (1951), Memoria provisional sobre el beneficio de las piritas en España. Madrid, cSIC.

Gomez MendozA, A. (1994), El "Gibraltar Económico«: Franco y Riotinto, 1936-1954. Civitas, Madrid.

- (1995), “Hacia una economía del frío: el Plan de Red Frigorífica Nacional, 1947-1951“. Documento de Trabajo 9512 de la Facultad de Ciencias Económicas y Empresariales de la Universidad Complutense de Madrid.

Gomez MendozA, A. y LOPEZ Garcia, S. (1992), "Los comienzos de la industria aeronáutica en España y la Ley de Wolf (1916-1929)", Revista de Historia Industrial, año 1 , núm. 1 , pp. 155-178.

Gonzalez Blasco, P., Jimenez Blanco, J. y Lopez Pinero, J.M. (1979), Historia y sociología de la ciencia en España. Alianza Editorial, Madrid.

Graham, M.B.W. y PruitT, B.H. (1990), $R \& D$ for Industry. A Century of Technical Innovation at Alcoa. Cambridge University Press, Cambridge -New York-.

HARMES-LIEDTKE, U. (1993), "Heinrich von Stackelberg y la economía nacional española", en García Delgado (coordinador), Economía española, cultura y sociedad. Homenaje a Juan Velarde Fuentes. Eudema, Madrid. pp. 553-572.

Helguera QUiJADA, J. (1992), "Las industrias artilleras en la época de Proust", en Garcia Hourcade, J.L. y Valles Garrido, J.M. (coordinadores), La Casa de la Química. Ciencia, artillería e ilustración. Ministerio de Defensa, Madrid. pp. 97-137.

Herrero Fernandez-Quesada, M.D. (1992), "El Real Colegio de Artillería de Segovia", en García Hourcade, J.L. y Valles Garrido, J.M. (coordinadores), La Casa de la Química. Ciencia, artillería e ilustración. Ministerio de Defensa, Madrid. pp. 35-46.

HoffmanN, W.G. (1958), The Growth of Industrial Economies. Manchester U.P., Manchester.

INE (Instituto Nacional de Estadística) (1988), Estadisticas sobre actividades en investigación científica y desarrollo tecnológico año 1985. INE, Madrid.

InSTITUTO (1920), Escuela Industrial de Barcelona: Instituto de Electricidad y Mecánica Aplicadas. Escuela Industrial de Barcelona, Barcelona.

INTA (Instituto Nacional de Técnica Aerospacial) (1962), Estatutos. Instituto Nacional de Técnica Aerospacial "Esteban Terradas". INTA, Madrid.

KEVLES, D.J. (1988), "Las instituciones científicas americanas, 1890-1930. La organización de la ciencia en la cultura práctica y pluralista", en Sánchez Ron, J.M. (coordinador) (1988), 1907-1987 La Junta para Ampliación de Estudios e Inves. tigaciones Científicas 80 años después. CSIC, Madrid. pp. 209-228.

Leiros, W., Beltrand, B., Magariño, L.A., Baldomero, M. y Martinez, G. (1977), Caminos abiertos por Santiago Ramón y Cajal. Hernando S.A. - CAMPM, Madrid.

LOPEZ FERNANDEZ, C. (1987), "Instituciones científicas e ideología en la España de 1940 a 1955", en IEC-ETSEIB (Grup de Treball d'Història de Ciència - Grup d'Historia de la Ciència i de la Tècnica), Cinquanta anys de ciència i tècnica a Catalunya. Entorn l'activitat científica d'E. Terradas (1883-1950). IEC, Barcelona, pp. 163-174.

LOPEZ GARCIA, S.M. (1991), "La organización de la investigación científica y técnica tras la Guerra Civil. Contrastes y similitudes con los logros de las primeras décadas del siglo XX", Encuentro de Historia Económica, (Actas de las ponencias). Valencia 7 y 8 de octubre, UIMP.

- (1992), “Un sistema tecnológico que progresa sin innovar”, Ekonomiaz. Núm. 22, $1^{\circ}$ cuatrimestre, pp. $30-55$. 


\section{El Patronato «Juan de la Cierva» (1939-1960)}

- (1994a), El saber tecnológico en la política industrial del primer franquismo. (Tesis doctoral), Universidad Complutense de Madrid, Madrid.

- (1994b) "El doble tañido de hierro. El tecnólogo José García Santesmases (19071989)", en Camarasa, J.M., Mielgo, H. y Roca, A. (coordinadors), (1994), I Trobades d'Història de la Ciència $i$ de la Técnica. SCHCIT/IEC, Barcelona. pp. 255-264.

LORA TAMAYO, M. (1946), "Organización actual de la Investigación Científica". Combustibles, año VI, núm. 33-34, may.-ago., pp. 76-88.

- (1969), Un clima para la ciencia. Gredos, Madrid.

LLAVE, J.S. de, (1921), “El Laboratorio Aerodinámico de Cuatro Vientos”. Ibérica, núm. 15 , pp. 52-55.

- (1926), “El laboratorio de Cuatro Vientos". Aérea, año IV, núm. 40, sep., pp. 3-9.

MAIOCCHI, R. (1980), "Il ruolo delle science nello sviluppo industriale italiano", en Micheli, G. Storia d'Italia. Scienza e tecnica nella cultura e nella società del Ri. nascimento a oggi. tomo III, Giulio Einaudi editore, Torino.

Mancomunitat de Catalunya (1923), L'Obra Realizada, 1914-1923. Mancomunitat de Catalunya, Barcelona.

MARTIN ACEÑA, P. y COMIN, F. (1991), INI: 50 años de industrialización en España. Espasa-Calpe (Biblioteca de Economía, Serie perfiles), Madrid.

MARTINEZ RUIZ, E. (1994), La intervención del INI en la industria de la defensa durante la autarquía (1941-1959), Documento de Trabajo 9408 del Programa de Historia Económica de la Fundación Empresa Pública.

Mosquera, C. y Coma-Cros, E. (1988), Ricart. Pegaso (La Pasión del Automóvil). Arcis Ediciones, Barcelona.

MOWERY, D.C. (1983), «The Relationship Between Intrafirm and Contractual Forms of Industrial Research in American Manufacturing, 1900-1940", Explorations in Economic History, núm. 20, pp. 351-374.

- (1992), "The U.S. national innovation system: Origins and prospects for change". Research Policy, vol. 21, pp. 125-144.

OCDE (1986), OCDE Science and Technology Indicators ( $R \& D$. Invention and Com. petitiveness). Núm. 2, OCDE, París.

- (1987), Innovation Policy, Spain. OCDE, París.

OCDE-CDTI (1976), La medición de las actividades científicas y técnicas, (traducción de The Measurement of Scientific and Technical Activities: Proposed Standard Practice of Surveys of Research and Experimental Development. Frascati Manual. OCDE, Paris. 1976). OCDE-CDTI, Madrid.

PASAMAR, G. (1991), Historiografia e ideología en la postguerra española: La ruptura de la tradición liberal. Prensas Universitarias de Zaragoza, Zaragoza.

Peset, J.L. (1986), “Introducción” en Muñoz, E. y Ornia, F., Ciencia y tecnología: una oportunidad para España. Aguilar, Madrid. pp. 13-39.

Prados Arrate, J. (1965), Plan de Desarrollo de España 1964-1967. Exposición y crítica. Tecnos, Madrid.

PresidenCIA DE Gobierno (1967). II Plan de Desarrollo Económico y Social. Presidencia de Gobierno, Madrid.

- (1972). III Plan de Desarrollo Económico y Social. Investigación Científica Y Desarrollo Tecnológico (1972-1975). Presidencia de Gobierno, Madrid.

Presupuestos Generales del Estado, 1946, 47 y 54. MEH, Madrid.

Puerto SARmiento, F.J. (1988), La ilusión quebrada. Botánica, sanidad y política cientifica en la España Ilustruda. Serbal/CSIC, Barcelona. 
Puig Raposo, N. y Lopez Garcia, S.M. (1992), Ciencia e industria en España. El Instituto Químico de Sarrià. IQS, Barcelona.

- (1994), "Chemists, engineers and entrepreneurs. The Chemical Institute of Sarrià's impact on spanish industry (1916-1992)", History \& Technology. Vol. 11, pp. 345-359.

RAMON Y CAJAL, S. (1991), "Deberes del Estado en relación con la producción científica" en Reglas y consejos sobre la investigación científica. Los tónicos de la voluntad, (12 edición). Espasa-Calpe, Madrid. pp. 160-190.

ROBINSON, H.J. y BARBER, B.B. (1971): Las inversiones norteamericanas en el desarrollo de España. Madrid, Stanford Research Institute y Cámara de Comercio Americana en España.

Roca Rosell, A. (1990), La Física en la Cataluña finisecular. El joven Fontserè y su época, (Tesis Doctoral). Departamento de Física Teórica. U.A.M.

Roca Rosell, A. y Sanchez Ron, J.M. (1990), Esteban Terradas. Ciencia y Técnica en la España contemporánea. INTA/Serbal, Madrid.

- (1992), Aeronáutica y Ciencia. Algaida/INTA, Sevilla.

RosenBerg, N. (1979), Tecnología y Economía. Gustavo Gili SA, Barcelona.

SAN RoMAN, E. ( 1993), "Una fuente para el Estudio de la industria española en la

- Gran Guerra: el Informe de 1919", Revista de Economía Aplicada. Vol. I, núm. 3, pp. 169-179.

- (1995), Los origenes de la SEAT. Madrid, Documento de Trabajo 9503 del Programa de Historia Económica de la Fundación Empresa Pública.

SANCHEZ RoN, J.M. (1988), “La Junta para Ampliación de Estudios e Investigaciones científicas 80 años después", en Sánchez Ron, J.M. (coordinador), 1907.1987 La Junta para Ampliación de Estudios e Investigaciones Científicas 80 años después. CSIC, Madrid. pp. 1-61.

- (1992), El poder de la ciencia. Historia socio-económica de la fisica (siglo XX). Alianza-Expo'92, Madrid.

Senent-Josa, J. (1977), Miseria y dependencia cientifica en España. Editorial Laia, Barcelona.

SHINN, T. (1988), “Progresos y paradojas en la ciencia y tecnología francesas, 1900-1930", en Sánchez Ron, J.M. (coordinador), 1907.1987 La Junta para Ampliación de Estudios e Investigaciones Científicas 80 años después. CSIC, Madrid. pp. 127-158.

SUDRIA, C. (1989), "Un factor determinante: la energia", en Nadal, J., Carreras, A. y Sudrià, C. (compiladores), La economía española en el siglo XX. Una perspectiva histórica. ( $3^{\mathrm{a}}$ edición). Ariel, Barcelona. pp. 313-363. 